\title{
DEVELOP AN INNOVATIVE COMPENSATION SOLUTION FOR FUNCTIONAL DISORDERS OF THE HAND
}

\begin{abstract}
Currently, in times of fierce market competition in selling goods and services for the disabled, quality and innovation are becoming "strategic weapons" for manufacturers. Depending on, inter alia, the dysfunctions of the injured person, the number of the offered products is increasing. For example: improving the functionality of the upper limbs is a highly significant issue, however due to the complexity of the functions and various degrees and types of restrictions, the treatment and rehabilitation process can be very complex and long-term, which at the same time does not guarantee full recovery. The authors describe the Polish invention created by Michał Jania, who will produce. This invention is intended to help people with upper limb illnesses and to assist with their rehabilitation.
\end{abstract}

Keywords: 3D printing, FFF, upper limb disorder, assistive eating apparatus, rehabilitation, 3DCENTRAL

\section{Introduction - a reference to the 3D central project}

Contemporary environment, rapidly changing needs and social preferences as well as strong and ever-increasing competition, force all organizations to change their operating mode. Changes in socio-economic conditions of many countries have led to changes in production, management as well as expansion of marketing activities. A manufacturer who is able to guarantee the desired product features such as: durability, convenience, reliability, attractive appearance, proper operation; without exceeding the price level in relation to competition, will have a chance to dominate the market with a given product for some time. However, a company wishing to maintain a competitive position on the market must, first and foremost, be in search of and implement innovative products (goods and services), strive for new technologies, new organizational forms in the integrated development of innovative business activities, exchange and manage knowledge, be in constant cooperation with other entities, that would result in transfer of information and knowledge within the given field.

Since 2016, in response to the market needs at the Faculty of Mechanics of Cracow University of Technology, an international project has been launched in a 10 partner consortium representing 10 regions of Central Europe, 3DCentral - Catalyzing

\footnotetext{
${ }^{1}$ mgr inż., 3D FLY

2 dr inż., Institute of Machine Technology and Production Automation, Faculty of Mechanical Engineering, Cracow University of Technology, e-mail: kielbus@m6.mech.pk.edu.pl
} 
Smart Engineering and Rapid Prototyping. The main objective of the project is to strive for European excellence in transnational cooperation dealing with exchange of technology, innovation, transfer and business efficiency in smart engineering and rapid prototyping. As part of a built platform for exchanging knowledge and experience between research and industry centers in the field of Smart Engineering and Rapid Prototyping, efforts have been made to create a specialized support program, a regional cooperation network. Actions taken aim at supporting strategic cooperation with experienced business partners, cooperation with partners in the development of 11 knowledge axes by connecting organizations and institutions as well as to promote the exchange or transfer of knowledge, knowledge and capital for development of products, services and/or solutions (a process that you can take up to generate an idea and eventually launch it to market).

Within the framework of the project and cooperation, Cracow University of Technology has cooperated with 3DFLY company and Mr. Michał Jania by conducting research that would create a device to compensate for functional dysfunction of hand. As part of the cooperation the company has become the sole producer of the device.

\section{Upper limb disorder}

Dysfunctions and deformations in the musculoskeletal and muscular-nervous system of limbs and spine as well as in the motion centers of the brain and spinal cord may cause motor disability. Because of the dysfunction of the motion organ, the term "disabled persons" refers to persons with limitation of upper and lower limbs or spine. Disorders, injuries and other pathological changes may limit the functioning of the upper limbs. Researchers and clinicians are constantly searching for new, more effective solutions to be used in therapeutic applications (MiKOŁAJEWSKA E., MiKoŁaJEWSKI D. 2012). Past injuries and accidents can affect the reduction of the natural mobility of joints of the upper limb, which directly affects their functional level.

Upper limbs enable people to perform basic functions, whereas their absence or limitation (permanent or temporary) is perceived as one of the most distressing. The degree of the upper limb functioning significantly influences the subjective (measured by the patient) and the objective (in terms of diagnostics) quality of life, as impairment, even of one upper limb, translates negatively mainly into:

- learning and working (handwriting, using a computer, driving),

- performing daily activities (personal hygiene, eating, etc.),

- contact with the immediate environment (touching, gripping, manipulation ability, feeling shape, texture, temperature), 
- participating in social life (giving hand, etc.) (MikOŁAJEWSKA E., MikOŁAJEWSKI D. 2012).

The majority of medical devices used in rehabilitation are used to improve, correct, stabilize or immobilize (LUM P.S.) (http://www.pwsz.nysa.pl/instytyty/piele gniarstwo/neurologia/udary_mozgowe.pdf).

The authors present the Polish invention of the Master of Physiotherapy, who since 2008 has been working with patients with intellectual and motor disability. $\mathrm{He}$ specializes in working with people who have been suffering from the disorder in the peripheral and/or central nervous system (brain) since birth or as a result of various factors. The product's official launch will be in June this year.

Qualified medical units for the Szermierz include:

- Cerebellum damage (ataxia) - lack of motor coordination and postural instability caused by abnormal functioning of the cerebellum (O'SULLIVAN SMITH C., Et al. 2004).

- Spinal cord injuries - annually 150 patients with spine injuries are only admitted to the Chair and Clinic of Rehabilitation of the Medical University of Warsaw (http://www.niepelnosprawni.pl/ledge/x/2706).

- Cervical myelopathy - a condition that involves a number of pathological conditions, the common feature of which is causing pressure on the spinal cord or large blood vessels that supply it, resulting in severe neurological symptoms. The basic symptoms of cervical myelopathy are various types of limb paresis, numbness, neck pain or tingling (COUGHLIN T.A., KLEZL Z. 2012, FERRITER P.J., et al. 2014).

- Infant cerebral palsy - is a syndrome of chronic and non-progressive central nervous system disorder (especially the central motor neuron) that results from brain damage before, after and during labor. The most common causes of the illness include: foetal hypoxia, birth pathology, bad foetal position and prematurity. Cerebral palsy is present in the general pediatric population in 2 cases per 1000, whereas children from the so-called disease risk, born of abnormal pregnancy and childbirth - in 5\% cases. Around 17 million people suffer from cerebral palsy all over the world (KERR GRAHAM H., et al. 2016).

- Muscular dystrophy - the term muscular dystrophy refers to a group of myopathies with a genetic background, with a constant progression. Although neuromuscular diseases differ from each other by their symptoms, pathology and clinical picture, it is advisable in all cases to improve the progressive muscle weakness, typical for the course of illness which, without intervention leads to functional impairment and distortion (KoSTERA-PRUSZCZYK A., RADWAŃSKA A., RYNIEWICZ B. (EDS.) 2010). 
- Other (polyneuropathy, malignancies, rotator cuff injuries ect.).

\section{Research methodology}

Secondary and primary market research was conducted within the project. Secondary market research has shown that the available ways of assisting the dysfunction of hand during eating is reduced to the passive lifting of fingers in the disabled hand. Therefore, a patient with a disabled limb will still have a problem while eating a meal. Additionally, the number of people suffering from upper limb disorder were analyzed.

Primary research was conducted in cooperation with physiotherapist Michał Jania.

Thanks to many years of experience of Mr Michal and his unconventional work based on in-depth analysis of patients' needs, he has developed a pattern and principles of AKJ operation. Primary research was based on observation and detailed interviews not only with patients but also with nurses and caretakers of the elderly people.

\section{Assiative eating apparatus "Szermierz" \\ 4.1. Construction and manufacturing method}

Assisting the handicapped person during the eating process is reduced to passive lifting of fingers of the disabled hand like in case of ManovoSpring apparatus. This method is inaccurate and imprecise because it does not support, in any way, the functioning of other joints of the upper limb i.e. the wrist, elbow or brachial joint. Patient with a disabled upper limb by using this device will not hold the fork properly while simultaneously moving the forearm, bending the arm and consequently will not be able to use the fork for eating purpose.

The assistive eating apparatus (AKJ, Szermierz) is characterized by a flat bar in the form of $3 / 4$ circle connected to the lower edge of the body on one side and the upper body section in the flat bar hole on the other. On the upper surface of the body there is a cutlery hole. The device allows for using the cutlery with a disabled hand in a fast and efficient way during the eating operation. Thanks to a simple construction, a disabled person can place a fork or a spoon in the device and then insert it into a disabled hand. The essence of "Szermierz" is the ability to put the upper limb in motion in the closed chain. This improves the stability of the limb, supporting weakened, disabled or paralyzed muscles of the shoulder, forearm and hand. The rolling motion gives the direction and allows the tip of the fork or spoon to be brought closer to the plate.

The photos show a prototype of the device made of acrylic glass by means of laser cutting. In the end, it was decided that the apparatus would be made by additive 
manufacturing method FFF (Fused Filament Fabrication). It belongs to a group of methods, where the process of creating a three-dimensional element is done in a layered manner by applying plasticized material and supporting material in the form of thin filaments using one or two heads (Fig. 2) 3 $^{3}$ The numerically controlled head has the ability to move in the $\mathrm{X}, \mathrm{Y}$ axes by applying the desired shape on the working platform.

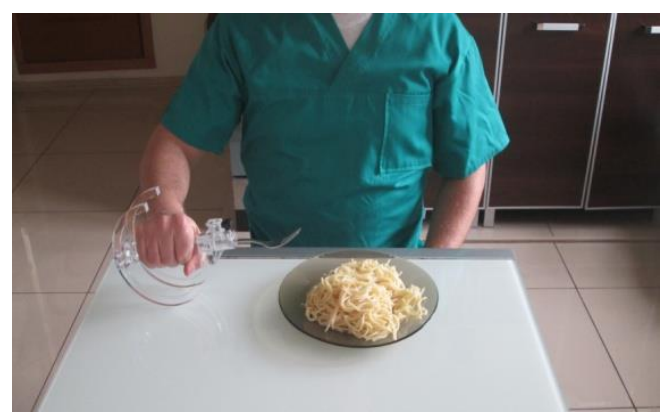

Fig. 1. Prototype of assistive eaeting apparatus.

Source: photo Michat Jania

This method enables manufacturing of custom-made assistive eating apparatuses while preserving appropriate strength parameters at a lower price than other methods available on the market. Finnotech PET-G material was used, which is distinguished by the following features:

- good sliding properties and wear resistance,

- prolonged high strength,

- excellent mechanical parameters: stiffness, durability, hardness, toughness, good resistance to repeated impact

- extremely low creep - lower than PA and POM,

- stability of dimension and shape, much better than PA and POM,

- low moisture absorption (lower than PA and POM),

- general thermal expansion lower than PA

- the product meets EU and FDA food contact requirements.

The manufactured PET-G filament has an ISO 10993 medical certificate. This allows the material to be used in contact with the skin for more than 30 days and even for subcutaneous use up to 30 days.

\footnotetext{
${ }^{3}$ www.engatech.com/difference-fdm-polyjet-3d-printing/
} 


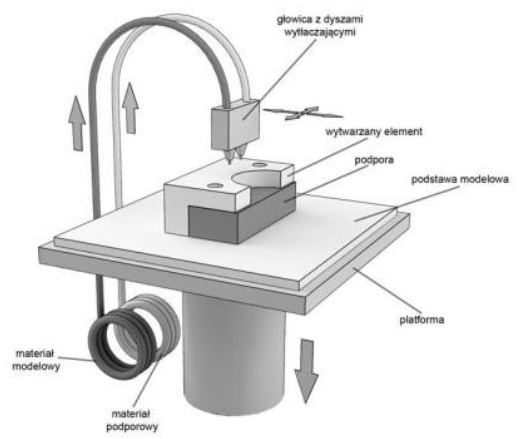

Fig. 2. FDM method functional diagram.

Source: GRABOWSKI M. 2016

\subsection{Sternal maneuver}

"Sternal maneuver" is a concept formulated by physiotherapist Michał Jania, the creator of AKJ, basing on the observations of patients' behavior during AKJ application and refers to the use of a patient's own sternum as a support to close the kinematic chain while aiming to the mouth with a fork. Most often patients use this maneuver as a result of weakening of forearm active pronation and weakening of the shoulder joint abduction/bending movement.

Assistive eating apparatus (AKJ) is one of the first mechanically-constructed medical devices on the market in terms of care equipment, compensating for hand functional deficiencies. The majority of medical devices in rehabilitation process are used to improve, correct, stabilize or immobilize.

By definition, functional compensation is the acquisition of the function of a disabled organ by another organ or instrument. In case of AKJ, the impaired function of the disabled upper limb (motion organ) is partially acquired by the apparatus.

However, it should not be confused with pathological compensation, where the body creates replacement mechanisms (dysfunctional - the hypermobility of one spine segment as a result of movement limitation of the adjacent segment, or metabolic osteophytes in response to instability of the joint). In case of functional rehabilitation, the pathological compensation is not proper motion patterns, which is based on abnormal, most often subconscious, use of the strongest muscle groups of the sick limb (or torso) to achieve the intended purpose (specific activity) 


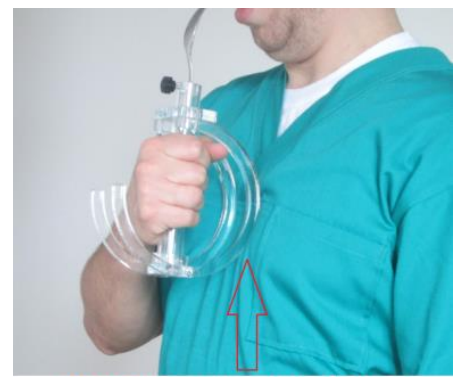

KINEMATIC CLOSED CHAIN
Fig. 3. Sternal maneuver.

Source: photo Michat Jania

\subsection{The use of Szermierza in neurology}

The AKJ apparatus, (especially in patients with neurological diseases) apart from the compensatory effect due to partial acquiring of functions, has also an improving effect. This is done through prorioceptive neuromuscular facilitation. The neuromuscular facilitation in terms of AKJ is performed by putting the upper limb into the normal motion pattern by means of kinematic closed chain. Movement in the correct upper limb pattern, which is characteristic for the use of cutlery, is possible thanks to the operation of the apparatus in several different planes. Movement in the kinematic closed chain of limbs is of great importance especially in paraparetic patients with shoulder girdle (e.g. stroke patients), forearm and hand, and in patients with impaired coordination of the limb (cerebellar damage). As a result of these disorders, patients have difficulties in maintaining stable upper limb as well as placing the fork in target, spilling soup using a spoon, lacking the strength to use a fork, and most often falling the cutlery out of the weakened hand (Fig. 4). The AKJ solves these problems by supporting the limb (closed chain) with simultaneous rolling motion. The supportive function increases the stability of the upper limb (the closed kinematical chain of the limb, which, in conjunction with the rolling motion (movement), allows for reaching the target (food).

In neurological patients without progressive disease (e.g. stroke), long-term use of AKJ will have an improving effect while using cutlery (Fig. 5). This will be the result of the effect of the described prorioceptive neuromuscular facilitation on the development of sensomotor disorders in the central nervous system (use of brain plasticity). Large number of repetitions = "modeling" of neural pathways. Assessing the improvement progress will be possible when the specialist separates the base of the AKJ from the wheel (possible disassembly) and then instructs the patient to use only the base with the attached cutlery during eating (without the wheel). Movement will then be performed in the kinematic open chain and if the patient performs it 
correctly it will be a sign of a considerable improvement. This is a functional test of the AKJ "Szermierz".

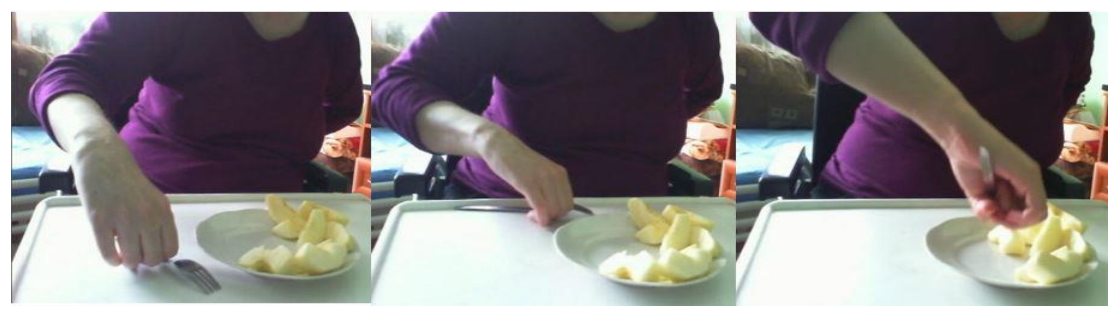

Fig. 4. Patient with spastic upper limb while eating without the use of AKJ. Source: photo Michat Jania

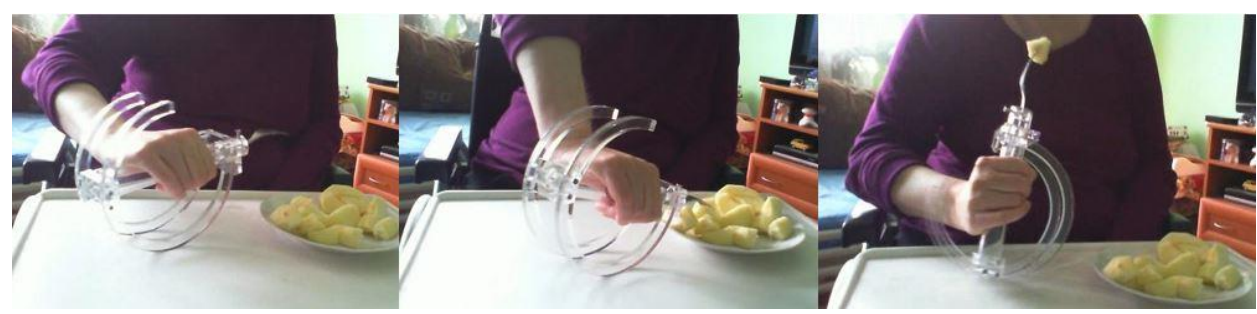

Fig. 5. Patient with spastic upper limb while eating with the use of AKJ.

Source: photo Michat Jania

Long-standing use of AKJ increases the overall efficiency of the entire upper limb (from the shoulder to the radial-wrist joint).

In patients with progressive diseases (such as Duchenne muscular dystrophy, multiple sclerosis, malignant brain tumors), the device is intended to prolong the independent use of cutlery (the psychomotor aspect).

In patients with irreversible upper limb dysfunction (contractures, paralysis) due to, for example, polyneuropathy, the assistive eating apparatus is often the only selfservice solution to food related activities.

\subsection{Using Szermierz in orthopedics}

The AKJ "Szermierz" can have a comprehensive therapeutic effect on soft tissue injuries within the shoulder girdle, such as rotator cuff damage. Closing the kinematic chain of the upper limb by AKJ relieves the muscles of the shoulder joint (including the supraspinous muscle) and provokes the cocontraction of the abductor - adductor antagonist muscles, provoking inner rotation of the shoulder joint. Internal rotation 
induces neurophysiological inhibition of the infraspinous muscle (function: external rotation). This action of the AKJ Szermierz affects the stabilization of the shoulder joint and the regeneration of the damaged supra- and infraspinous muscles by relieving them of food-related activities.

The use of AKJ in orthopedics is of particular importance for patients with painful ailments that directly influence the mobility of the shoulder joint and indirectly (functionally) the entire limb e.g. humeral head osteonecrosis.

Szermierz can be used as a form of limb relief (closed chain movement) before and after upper limb surgery (fractures, operation of joints, muscles, ligaments).

\section{Summary}

The contemporary market of goods and services, including the market of goods and services for the disabled, is characterized by strong and ever-growing competition and constant economic and technological transformations. Having these conditions in mind, quality and innovation becomes an important factor in the fight for customers. Companies seek to gain and maintain their market position by finding ways to convince the customers that their products or services are competitive and represent the level that is adequate to the expectations of their buyers, highlighting their necessity in their daily lives. The customer when judging, must be convinced that the company is able to guarantee certain quality and meet one's expectations. On the other hand, customer satisfaction, that is reflected in the quality of goods and services, is the source of customer loyalty towards the company, its products or services, which is the basis for developing positive relations and further, often long-term, cooperation. In the struggle to win the favor of a disabled customer, companies are outdoing each other in finding new solutions that will improve the daily functioning of such people. For example in case of other disorders during walking, rehabilitation crutches are used to compensate for the motor deficiencies. Crutches close the kinematic chain and thus increase the stability while standing or walking. This is done to compensate for imbalances or paresis of the lower limb muscles. Until now there hasn't been an available device that would compensate for upper limb disorders. The Assistive Eating Apparatus also known as Szermierz, is a Polish patented invention that enables the patients for self-handling of cutlery without the help of a caretaker.

The apparatus was created for the self-service of a 17-year-old patient with hemiparesis and moderate intellectual disability staying in a rehabilitation and education center. Patient diagnosed with infant cerebral palsy.

AKJ is manufactured by the FFF method using PET-G material, which can be adapted to the patient's needs on regular basis. 
The device is also intended to aid employees of hospitals and nursing homes and caregivers by relieving them from feeding of patients.

One must keep in mind that by providing your customers with the right product that meet their quality expectations, the company gains good reputation and may expect the customer to return and even promote the company's products by recommending them to their partners, which helps in expanding the market.

\section{Bibliography}

1. BŁaszczyK M., DrapaŁa A., GierczyńsKi J., Gryglewicz J., JaWorska U., KARCZEWICZ E., SIELICKI P., ZALEWSKA H., ZYŚK R. (EDS.) 2014. Społeczno-ekonomiczne skutki stwardnienia rozsianego (SM) w Polsce. IZWOZ, Warszawa.

2. Coughlin T.A., Klezl Z. 2012. Focus On Cervical Myelopathy, British Editorial Society of Bone and Joint Surgery.

3. ENGATECH R\&D [online], www.engatech.com/difference-fdm-polyjet-3d-printing/

4. Ferriter P.J., MAndel S., DeGregoris G., Kamara E., Aydin S.M. 2014. Cervical Myelopathy, Practical Neurology, April.

5. GRABOWSKI M. 2016. Zastosowanie metody warstwowego osadzania stopionego materiatu (FDM) w medycynie, Inżynieria biomedyczna : metody przyrostowe w technice medycznej, Politechnika Lubelska.

6. Kerr Graham H., Rosenbaum P., PAneth N., Dan B, Lin J.P., Damiano D.L., Becher J.G., Gaebler-Spira D., Colver A., Reddihough D.S., Crompton K. E., Lieber R. L. 2016. Cerebral palsy, Nature Reviews, Volume 2.

7. Kostera-Pruszczyk A., RAdwańska A., Ryniewicz B. (Eds.) 2010. Dystrofie mięśniowe. Warszawa Wydawnictwo Lekarskie, PZWL.

8. Lo Ho SHING, Exoskeleton robots for upper-limb rehabilitation: State of the art and future prospects, Medical Engineering and Physics, Volume 34, Issue 3, 261-268.

9. LUM P.S., Robot-assisted movement training compared with conventional therapy techniques for the rehabilitation of upper-limb motor function after stroke, Archives of Physical Medicine and Rehabilitation, Volume 83, Issue 7, pp. 952-959.

10. Mikolajewska E., MikoŁaJewsKi D. 2012. Nowoczesne rozwiazania techniczne w usprawnianiu funkcji kończyn górnych, Annales Academiae Medicae Silesiensis, 66, 4, pp. 34-40.

11. Niepełnosprawni.pl [online], http://www.niepelnosprawni.pl/ledge/x/2706;

12. O’Sullivan Smith C., Michelson S.J., BennetT R.L., BiRD T. D. 2004. Spinocerebellar Ataxia: Making an Informed Choice About Genetic Testing, Medical Genetics and Neurology University of Washington Medical Center, November.

13. Państwowa Wyższa Szkoła Zawodowa w Nysie [online] http://www.pwsz.nysa.pl/instytyty/pielegniarstwo/neurologia/udary_mozgowe.pdf 